\title{
The Semantic Primitive Structures of the Anger-type Psychological Adjectives in Modern Chinese
}

\author{
Gao $\operatorname{Lin}^{1}$, Hu Dan ${ }^{2, *}$ \\ ${ }^{1}$ College of Foreign Languages, Wuzhou University, China \\ ${ }^{2}$ School of Foreign Studies, Zhongnan University of Economics \& Law, China
}

Received February 3, 2020; Revised March 10, 2020; Accepted March 19, 2020

Copyright $\odot 2020$ by authors, all rights reserved. Authors agree that this article remains permanently open access under the terms of the Creative Commons Attribution License 4.0 International License

\begin{abstract}
The rapid development of computational linguistics has put forward higher requirements for accurate semantic perception. As the foundation of the semantic understanding of natural language, much previous research has focused on the micro-structure of word meanings of different parts of speech and its sub-categories. This paper takes the anger-type psychological adjectives in modern Chinese as the research object and studies its semantic structures under the guidance of semantic primitive theory by describing the semantic features and the semantic primitive structural attributes, conducting the semantic analysis, extracting the semantic primitives and building a semantic primitive set of the anger-type psychological adjectives in modern Chinese. The result of this paper clarifies the similarities and differences between the meanings of all the anger-type psychological adjectives and solves the problems of circular and identical definitions in dictionaries, which to some extent is helpful in providing support for machines in language understanding and automatic language production therefore improves the speed and accuracy of language processing.
\end{abstract}

Keywords The Anger-type Psychological Adjectives, Semantic Features, Semantic Primitive Structural Attributes, Semantic Analysis, Semantic Primitive Extraction

\section{Introduction}

The advert of the information age and the subsequent interplay between computer sciences and linguistics demand accurate descriptions of word meanings in natural language processing; therefore, more and more attention has been paid to the study of the micro-structures of word meanings. As the basic materials to describe the micro-structures of word meanings, the extraction of semantic primitives is the first step in the construction of the large-scaled semantic knowledge base. Scholars both at home and abroad have made great attempts to extract semantic primitives and magnificent achievements in the fields of natural language, dictionary interpretation and language engineering. In natural language, Wierzbicka and her team have extracted over 60 semantic primitives from about 30 languages in the world, and the 60 semantic primitives are generally shared by all these languages.[1] In lexicography, basic words are extracted as explanatory primitives to define other words.[2] In semantic calculations, Dong's HowNet decomposes concepts into the smallest meaning unit "sememe", and it has extracted 2199 seme mes to depict concepts instead of meanings.[3] $\mathrm{Hu}$ takes metric adjectives in Chinese as examples and extracts 36 semantic primitives.[4]

As one sub-category of psychology adjectives, meanings of the anger-type psychology adjectives in modern Chinese are abstract, internalized and ambiguous, which makes them difficult to study. The most obvious problem about these words is the circular and identical definitions in dictionaries, which sometimes confuses both human beings and computers in language understanding. In addition, the current research on the anger-type psychological adjectives in modern Chinese mainly focuses on its syntax, semantics, grammar and prag matics, but the research on the internal structures of word meanings is very limited. Zhao lists 11 basic anger-type psychological adjectives in his doctoral thesis, and sets up five elements of the semantic feature, namely, semantic class, semantic orientation, semantic primitive, original quantity feature, and social meaning. Furthermore, he extracts the paradigmatic semantic feature and establishes the semantic identity (ID) of each anger-type psychological adjective according to the dictionary definition and cognitive judgment. [5] While his study is not precise enough in identifying the nuance of the word meanings. 
This paper takes the anger-type psychological adjectives in modern Chinese as the research object with different entry of words, different research methods, and different results from that of Zhao's, aiming to analyze its semantic features and extract the semantic primitives under the guidance of semantic primitive theory. The research questions are as follows: 1 . What are the semantic features and semantic primitive structural attributes of the anger-type psychological adjectives in modern Chinese? 2. What are the semantic primitive units of the anger-type psychological adjectives in modern Chinese?

\section{Research Methodology}

\subsection{Sources of Research Data}

In collecting the anger-type psychological adjectives in modern Chinese, the entry selection criteria in this study takes "definition" and "part of speech" into consideration. As Modern Chinese Dictionary $\left(7^{\text {th }}\right.$ edition) gives a comprehensive part-of-speech tagging for all the words in it, this paper adopts this part-of-speech tagging and takes any word which is tagged as adjective with the meaning of describing people's angry psychological activities and its external expressions as the anger-type psychological adjective. In addition, it is well known that the distribution boundary of parts of speech in Chinese are fuzzy, especially the boundaries between nouns and verbs, verbs and adjectives. $\mathrm{Lu}$ points out that there does exist a phenomenon that some Chinese words have both types of part-of-speech in language. [6] Since psychological adjectives are very close to psychological verbs in semantics, the boundary between them is not clear. As for the boundary between adjectives and verbs, this paper adopts Zhu's distribution standards, which main ly include three points. Firstly, the predicate that can be modified by adverbs of degree but cannot take objects is an adjective. Secondly, predicates that are not modified by adverbs of degree nor take objects are verbs. In Chinese, there are some Chinese words can be modified by adverbs of degree and followed by objects respectively, but they cannot be modified by adverbs of degree and followed by objects simultaneously. For example, the Chinese word “委曲 (aggrieve)" can be used as a verb when taking objects and an adjective without objects. Thirdly, words that can either be reduplicated with the verb model of "ABAB" or the adjective model of "AABB" belong to both of verbs and adjectives, such as “高兴 (happy)”, “漂亮 (pretty)”.[7] Under such distribution standards, some words tagged as verbs in Modern Chinese Dictionary ( $7^{\text {th }}$ edition), such as “愤恨(resent)”, “满意(satisfy)”, etc., meet the criteria of adjectives; therefore, they can be used as adjective. Such words are called multi-category words. This paper also classifies such multi-category words into adjectives.

The research sources in this paper include two parts.
Firstly, entries of the anger-type psychological adjective in modern Chinese and the definitions are chiefly derived from Modern Chinese Dictionary ( $7^{\text {th }}$ edition), and supplemented by Dictionary of Modern Chinese Adjective, A New Dictionary of Chinese Adjectives, Dictionary of Chinese Adjective Usage and Dictionary of Modern Chinese Classification.[8][9][10][11][12] Secondly, the semantic analysis and extraction of the semantic primitives of the anger-type psychological adjectives in modern Chinese mainly inspired by The Chinese Dictionary 2.0 (electronic version), Dictionary of the Origin and Development of Chinese Characters, CCL corpus developed by the Chinese Linguistics Research Center of Peking University, and the online corpus developed by Computational Linguistics Research Laboratory, Language and Character Application Research Institute, the Ministry of Education, etc.[13][14][15][16]

\subsection{Sample Collection}

As one of the four basic human emotions, anger is an unpleasant feeling caused by unfair treatment and unacceptable frustration. The anger-type psychological adjectives in modern Chinese describe people's angry psychological activities, internal psychological state or external man ifestations, which is a closed sub-category of psychological adjectives with limited numbers. Dong, editor-in-chief of Dictionary of Modern Chinese Classification, lists 17 adjectives exp ressing anger: 愤怒 (fèn nù), 愤慨(fèn kăi), 悲愤(bēi fèn), 气愤(qì fèn), 气 恼(qì năo), 愤愤(fèn fèn), 愤然(fèn rán), 悻悻 (xìng xìng), 悻然(xìng rán), 怒冲冲(nù chōng chōng), 气呼呼 (qì hū hū), 怒不可遏 (nù bù kě è), 怒火中烧 (nù huǒ zhōng shāo), 怒发冲冠(nù fà chōng guān), 令人发指 (lìng rén fà zhî), 暴跳如雷(bào tiào rú léi), 七窍生烟(qī qiào shēng yān).[12] This is the early collection of psychological adjectives that describes anger. Zhao sums up 11 psychological adjectives expressing anger in his doctoral thesis The Semantic Network of Psychological Adjectives in Modern Chinese): 愤慨(fèn kăi), 愤恨(fèn hèn), 愤潄(fèn mèn), 愤怒(fèn nù), 激愤 ( jī fèn), 愤激 (fèn jī), 愤然(fèn rán), 气愤(qì fèn), 气恼(qì năo), 狂怒 (kuáng nù) and 恼怒(năo nù).[5]

On the entry selection criteria of the anger-type psychological adjectives in modern Chinese, the words that Dong lists include disyllabic words, trisyllabic words and four-syllable words. While those that Zhao collects are all disyllabic words. They both ignore monosyllabic words. However, it is well known that monosyllabic words are at the basic level in the Chinese vocabulary system, and some of them are semantic primitives, an important component of other semantic structures. According to the explanation of part-of-speech tagging in Modern Chinese Dictionary $\left(7^{\text {th }}\right.$ edition), although some single-character items are words and some are morphemes, 
the monosyllabic words are also included in this paper owing to the fact that some semantic primitives are words (e.g. free semantic primitives) while some are not words (e.g. adherent semantic primitives).[4] In addition, due to the loose structures and the semantic and grammatical particularities of the four-character idioms, this paper temporarily excludes them.

After exhaustive collection and collation, this paper lists 36 anger-type psychological adjectives in modern Chinese from Modern Chinese Dictionary ( $7^{\text {th }}$ edition). The word set of the anger-type psychological adjectives in modern Chinese is listed below:

Table 1. The word set of the ATPA in modern Chinese

\begin{tabular}{|c|c|}
\hline $\begin{array}{l}\text { monosyllabl } \\
\text { es }(8)\end{array}$ & $\begin{array}{l}\text { 愤(fèn), 怫(fú), 慨(1)(kǎi)), 忾(kǎi)), 濏(2)(mèn), } \\
\text { 恼(1)(năo), 怒(nù), 愠(yuun) }\end{array}$ \\
\hline $\begin{array}{l}\text { disyllables } \\
(23)\end{array}$ & 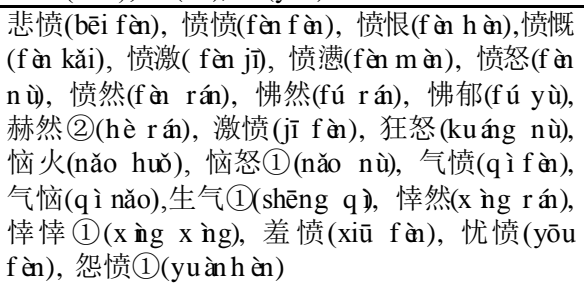 \\
\hline $\begin{array}{l}\text { trisyllables } \\
\text { (5) }\end{array}$ & $\begin{array}{l}\text { 怒冲冲 (nù chōng chōng), 气冲冲 (qì chōng } \\
\text { chōng), 气鼓鼓(qì gŭ gŭ), 气哼哼 (qì hēng hēng), } \\
\text { 气呼呼(qì hū hū) }\end{array}$ \\
\hline
\end{tabular}

\subsection{Theoretical Framework}

At present, studies on the micro description of word meanings are mainly represented by theories of sememe analysis and semantic primitives. Sememe analysis theory has developed from the basic idea that "A word can be broken down into a set of microcosmic semantic structure" proposed by a Danish school representative L. Hjelmslev in 1940's to the basic method of European and American modern semantics in 1970's, it breaks the restrictions of traditional semantics that considers "morpheme" as the smallest semantic unit, and puts forward that sememe is the smallest constituent unit and the most basic structure particle of word meanings from the perspective of semantic components.[17] In practice, sememe analysis theory uses modern decomposition methods to substantiate meaning, revealing the meanings of words, strengthening the semantic analyticity, and providing a fine interpretation of word mean ings. Meanwhile, seme me analysis displays the semantic relationship among words in the vocabulary system, helping people better understand and explain the semantic aggregation of various words, which is conducive to the extraction and analysis of sememe.[18] However, sememe analysis theory also has obvious defects. Firstly, the extraction of sememe and the analysis of word structures are too subjective and arbitrary due to its non-unified standards and operating procedures, so, it is difficult to guarantee the consistency of the system; secondly, it is difficult to secure the efficiency and accuracy of semantic calculations since the sememe set is open and the number of the sememes is not controllable. [4]

People have been studying the semantic primitive theory for a long time. Since the 17th century, philosophers and logicians have been exploring primitives. Analytic geometry, founded by the French mathematician and philosopher Descartes, successfully connects mathematics and geometry through universal symbols, and on this basis, it puts forward the tentative idea of constructing "universal language".[19] German mathematician and philosopher G. W. Leibniz once compared the undefined "primitives" to "the Alphabet of Human Thoughts", and advocated to seek the smallest basic concepts from natural languages.[20] Famous French theologian and philosopher Antonie Arnauld of the mid-17th century once said, "Furthermore, I say it would be impossible to define every word. For in order to define a word it is necessary to use other words designating the idea we want to connect to the word being defined. And if we again wished to define the words used to explain that word, we would need still other words, and so on to infinity. Consequently, we necessarily have to stop at primitive terms which are undefined."[21] As a continuation of linguistic philosophy, in order to avoid circular argu ments in the interpretations of word meanings, or explain simple words with complex words and cultural deviations when interpreting foreign words, Wierzbicka founded Natural Semantic Metalanguage (NSM) on the basis of logical metalanguage, which is an important semantic theory in the late 20th century.[22] NSM assumes that all human languages have a core that covers the most basic and universal meanings, which is called the semantic primitive.[20]

Based on the above research, Professor $\mathrm{Hu}$ further develops the semantic primitive theory. In his study, primitives are regarded as the smallest semantic particles and the most basic components of word meanings, and diffe rent primitives reflect different characteristic attribute dimensions of word meanings. Semantic primitive theory believes there is an astronomical number of lexical items in a language system, but the underlying rules governing their internal structure are limited, therefore, the semantic primitive set should be a closed one with limited nu mbers. In addition, this theory uses unified standards and operating procedures to describe the semantic features of each word class and extract their semantic primitives, and thus the finite semantic primitives and semantic primitive equations can be used to describe the infinite vocabulary system.[4] According to Hu's interpretation of semantic primitive theory, the meanings of a word is actually a primitive compound structure, and the materials of the structure come from a finite set of semantic primitives. The rules of primitive combination follow the constraint of the lexical structure equation. The types and quantities of semantic primitives vary from language to language, and the semantic primitives of different kinds of 
vocabulary (for example, divided by part of speech) differ from each other even in the same language. Semantic primitives are the carriers of the conceptual meaning and additional meaning of a word and the dominant factors of its semantic features. All the semantic features of a word are generated by the different semantic primitives that constitute the word. [4]

$\mathrm{Hu}$ also classifies the functions of semantic primitives into three types: constant primitives, variable primitives and assignment primitives. When describing word meanings, there are some invariant semantic primitives shared by all the words in the same subset called constant primitives. Additionally, there are also some primitives reflecting the differences of individual characteristics, which often present symmetrical or parallel distributions in the smallest lexical subset. For any particular word, the variable primitive in its semantic structure must have a fixed value. The ranges of variable primitives are very complex since they can be a composite primitive combination (i.e. a non-primitive word) or a simple primitive. These simple primitives are often used only as the values of variable primitives, so they can be called assignment primitives. And at the semantic level, each semantic attribute and its value are expressed by one semantic primitive or a primitive cluster composed of a group of semantic primitives. In order to express these semantic primitives, $\mathrm{Hu}$ uses $\mathrm{G}[\mathrm{A}]^{1}$ to express single semantic primitive and $\operatorname{Gs}[\mathrm{B}(\mathrm{C})]^{2}$ a semantic primitive cluster.[4] This paper regards semantic primitive theory as the theoretical framework and adopts Professor Hu's expressions of semantic primitives.

\section{Semantic Features and Semantic Primitive Structural Attributes of the Anger-type Psychological Adjectives in Modern Chinese}

\subsection{Semantic Features of the Anger-type Psychological Adjectives in Modern Chinese}

Generally speaking, the meanings of a word consist of two parts: conceptual and additional meaning. Conceptual meanings are the essence of a word and the basic content of its meanings, to which color meanings are attached. [23] The anger-type psychological adjectives in modern Chinese is one sub-category of psychological adjectives in modern Chinese; as a result, their meanings must have both the characteristics of general psychological adjectives and the unique semantic features of its own.

1 A represents any semantic primitive.

2 B represents variable primitive and $\mathrm{C}$ assignment primitive(the value of variable primitive)
3.1.1. Objects Described by the Anger-type Psychological Adjectives and Their Semantic Core in Modern Chinese

First of all, since the main function of adjectives is to describe or modify the properties and states of other objects, having the specific descriptive objects is a basic semantic character of adjectives. The anger-type psychological adjectives in modern Chinese describe people's angry psychological activities and its external expressions, so the object it describes can be identified as human, and the object is characterized by emotion. Secondly, since the basic meaning of a word is the core of its meaning, the basic meaning of the anger-type psychological adjective “怒(angry)” can be determined as its semantic core.

\subsubsection{Manners of the Anger-type Psychological Adjectives in Modern Chinese}

Psychology argues that human emotions not only have internal psychological reactions, but also the corresponding external appearances. The semantic features of the angry-type psychological adjectives in modern Chinese are also reflected by the different ways that they emphasize the same semantic core "angry". For example, “愤慨(fèn kăi)” means “气愤不平(angry and scornful, esp at in justice or undeserved blame, etc)," “恼 火(năo huǒ)” means “生气(annoyed)”. Words “愤慨(fèn kăi)” and “恼火 (năo huǒ)” in the above examples emphasize the internal reactions of "anger". On the contrary, some reduplicated anger-type psychological adjectives ending up with “然(rán)" are often used to describe the external "appearance" of anger, and highlight its external manifestations, such as “愤愤(fèn fèn)” has the meaning of “很生气的样子(appearing to be resentful because of unfair treatment, etc) ”, “气冲冲(qì chōng chōng)" is a state word, meaning “形容非常生气的样子 (the angry look when one is in a really bad temper)".

Clearly, the manners of the anger-type psychological adjectives not only emphasize the internal psychological reactions of anger but also highlight its corresponding external appearance.

\subsubsection{Psychological States Expressed by the Anger-type Psychological Adjectives in Modern Chinese}

Human emotions are psychological activities and inner states produced by a variety of senses, thoughts and behaviors. Under different conditions, people's psychological activities have different states, including the single dimension emotion and the co-existence of multi-dimensional emotions. The former indicates the static state of mind, while the latter shows the dynamic state. According to the observations of the anger-type psychological adjectives in modern Chinese in this paper, besides "anger", other emotions are mostly accompanied simultaneously. For example, “恼 (1)(năo)” means “生 气”(annoyed, slightly angry), “怒(1)(nù)” means “愤 
怒”(angry), “赫然(2)(hè rán)” 形容大怒(furious), “气恼 (qì năo)" has the meaning of “生气; 恼怒 (annoyed; irritated)”. Words such as “恼(năo)”, “怒(nù)”, “赫然(hè rán)”, and “气恼(qì năo) "describe a static state of mind that is purely caused by anger, while other adjectives such as “愤激(fèn jî̀)”, “差愤(xiū fèn)”, “忧愤”(yōu fèn), and “怨愤(1)”(yuàn fènt) involve “anger”, “shame” and other emotions; therefore, they indicate emotional changes, so the states of mind they describe are changing and dynamic.

\subsubsection{Degrees of the Anger-type Psychological Adjectives in Modern Chinese}

Degree is a typical semantic feature of adjectives, while the description of degrees that the anger-type psychological adjectives reflect is related to the a mbiguity of word meanings, which has been studied by scholars for a long time. Nowadays, it is commonly believed that fuzziness is a typical semantic feature of natural languages. [24] Because of the fuzziness of language, some words cannot be accurately depicted and even measured. As a result, descriptions about the degrees of the anger-type psychological adjectives in modern Chinese can only be roughly ranked but not precisely determined. Zhang argues that Chinese adjectives can be used to express different levels of quantities in combination with the degree words such as slight, medium, high and extre mely high in language use.[25] Zhao divides the psychological adjectives expressing anger into four grades “生气(shēng qii)”, “气愤(qì fèn)”, “愤怒(fèn nù),” “狂怒(kuáng nù)” and ranks them from "slight", "medium", "high" to "extreme high".[5] Based on the above research on the degrees of Chinese adjective and the different degrees expressed by the angry-type psychological adjectives in modern Chinese, this paper classifies them into five grades: “生气(shēng qì)”, “气愤(qì fèn)”, “愤怒(fèn nù),” “愤恨(fèn hèn)” and “狂怒(kuáng nù)” and ranks them from "slight", "medium", "high", "higher" to " highest".

\subsubsection{Polarity of the Anger-type Psychological Adjectives in Modern Chinese}

Generally speaking, people will produce positive emotions if their needs are satisfied, otherwise they will produce negative emotions. In this way, human emotions have positive polarity and negative polarity. Polarity is an important semantic character of adjectives, yet most of the studies on the polarities of words do not distinguish between semantic polarity and pragmatic polarity given the fact that there are some negative emotions such as sadness, anger, and so on, but that doesn't mean the words used to describe the negative emotions are negative words. For instance, semantically speaking, the word "angry" has a negative meaning, but if it is used in sentence like "people are angry about the atrocities committed by terrorists", the word "angry" cannot be labeled as negative; on the contrary, it is an expression of justice and fairness.
This example indicates that pragmatically speaking, the word "angry" might have positive polarity, therefore, the polarities of the anger-type psychological adjectives in modern Chinese should not be simply categorized as neither passive nor negative but considered from both semantic and prag matic perspectives. Since the focus of this paper is on semantics, the polarity the anger-type psychological adjectives in modern Chinese is determined as negative, and its pragmatic polarities should be judged according to the specific context.

\subsubsection{Pragmatic Characters of the Anger-type Psychological Adjectives in Modern Chinese}

The pragmatic features of the anger-type psychological adjectives in modern Chinese are mainly reflected in rhetoric, grammatical collocation, word frequency and so on. At the rhetorical level, the anger-type psychological adjectives in modern Chinese have stylistic features such as spoken and written language, for example, the stylistic feature of word such as “怫然(fú rán)” is written language. In grammatical collocation, there are mainly the grammatical functions of predicates and attributes, namely, some anger-type psychological adjectives in modern Chinese can be used as predicates and attributives, while some cannot. Generally speaking, words used to describe outward manifestations of anger such as “悻然(xìng rán)” can be used as attributes rather than predicates. In addition, word frequency is a part of semantic study, and there is a distinction between common words and uncommon words. According to CCL corpus, for instance, there are 7392 concordances with “愤 怒 (fèn nù)”, but only 14 concordances with “怫郁(fú yù)”. Obviously, the former is a common word, while the latter uncommon word.

\subsection{Semantic Primitive Structural Attributes of the Anger-type Psychological Adjectives in Modern Chinese}

The basic meaning and additional meaning of a word reveal certain components or attributes of word meanings from different aspects, but it cannot reveal the internal semantic structures and its structural rules. Different parts of speech have different semantic structures, which are reflected in the dimensions of semantic attributes and their values. [4] The meanings of adjectives are highly integrated with their syntactic objects, since the main function of adjectives is to describe or modify the properties and states of other objects. Therefore, the semantic composition of adjectives not only includes its semantic type and semantic core, but also the semantic attributes and pragmatic attributes, as these semantic primitives often carry the attributes of the objects they modify or describe.

The meaning of an adjective is composed of its semantic core, the object it describes and its semantic features. Therefore, for different objects, or for the same 
object with different semantic attributes, even if the core content described is the same, the adjectives used may be different. [26] As one sub-category of adjectives, the semantic primitive structural attributes of the anger-type psychological adjectives in modern Chinese include the semantic core, the object it describes, the semantic features of the object and its corresponding values.

3.2.1. Primitives of the Semantic Core and the Object of the Anger-type Psychological Adjectives in Modern Chinese

As mentioned above, the semantic core of the anger-type psychological adjectives in modern Chinese is "angry", which is expressed as G[angry]. The anger-type psychological adjectives are used to describe people's angry psychology; therefore, the object it describes can be identified as human, and the character of the object is emotion, which can be expressed by the primitive cluster Gs [human(emotion)].

\subsubsection{Semantic Attributes and Their Values of the Anger-type Psychological Adjectives in Modern Chinese}

On the basis of the "object" and its character "emotion", together with the most basic semantic attributes of the anger-type psychological adjectives in modern Chinese and their semantic features, this paper expresses the semantic attributes and its values as the followings: Gs [manner (internal, external)], Gs [psychological state (static, dynamic)], Gs [degree(slight, medium, high, higher, highest)], Gs[polarity (negative)], Gs[style (spoken, written)], Gs[predicate(positive, negative)], Gs [attributive(positive,

negative)], Gs[multi-category(positive, negative)], and Gs[word frequency(common, uncommon)].

\section{Semantic Primitive Extractions of the Anger-type Psychological Adjectives in Modern Chinese}

\subsection{Principles and Operating Procedures of Semantic Primitive Extraction}

The semantic primitive extraction in th is paper follows the four principles proposed by $\mathrm{Hu}$ : the combination of rationalis $m$ and empiricis $m$, the combination of top-down and bottom-up, the combination of predefinition, analysis and extraction, and the combination of Chinese language knowledge and encyclopedic knowledge. Firstly, the combination of rationalis $\mathrm{m}$ and empiricis $\mathrm{m}$ means conducting the semantic analysis and extracting the semantic primitives from the linguistic structure rules with the method of empirical statistics on the basis of language facts. Secondly, the combination of top-down and bottom-up methods uses the concept of classification tree to divide the whole vocabulary from top to bottom layer by layer to determine the smallest lexical field of certain word class, and that is the way how the lexical field of the anger-type psychological adjectives in modern Chinese is built; The bottom-up approach is to analyze and extract the semantic primitives of each minimal semantic group in this field. Thirdly, the combination of predefinition, analysis and extraction means that certain semantic primitives can be predefined by describing the semantic features of words and analyzing their semantic primitive structural attributes. Finally, the combination of Chinese language knowledge and encyclopedic knowledge indicate language is the main carrier of human thought and culture as well as knowledge dissemination and inheritance. It is well known that vocabulary is regarded as the most basic structural material of language, so it will inevitably contain lots of encyclopedic knowledge. [4] Therefore, both the Chinese language knowledge and the encyclopedic knowledge need to be taken into account in order to extract semantic primitives accurately and comprehensively.

Based on the above principles of semantic primitive extraction, together with the semantic features of the anger-type psychological adjectives in modern Chinese, this paper works out the operating procedures of semantic primitive extraction as follows: "Establish the minimum lexical field $\rightarrow$ Conduct semantic analysis $\rightarrow$ Extract semantic primitive $\rightarrow$ Verify $\rightarrow$ Incorporate and optimize $\rightarrow$ Build a semantic primitive set".

Step 1 Establish a minimum lexical field. After exhaustively collecting and collating the authoritative dictionaries such as Modern Chinese Dictionary $\left(7^{\text {th }}\right.$ edition), this paper builds a word set of the anger-type psychological adjectives in modern Chinese with 36 words, which is the minimal lexical field of this study.

Step 2 Conduct semantic analysis. According to the definitions and examples of the anger-type psychological adjectives in modern Chinese from Modern Chinese Dictionary $\left(7^{\text {th }}\right.$ edition) and other dictionaries and CCL corpus, together with the author's own understanding of language, this paper analyzes the semantic meanings of each group in the set of the anger-type psychological adjectives in modern Chinese and makes a semantic analysis table to compare the similarities and differences of the word meanings in each group.

Step 3 Extract the semantic primitives of each group of the anger-type psychological adjectives in modern Chinese, and establish the corresponding semantic primitive set on the basis of the above steps.

Step 4 Verify. Firstly, summarize all the semantic analysis of each group and make a general semantic analysis table of the anger-type psychological adjectives in modern Chinese. Secondly, observe and compare the semantic structural attributes of each word in the table. If there is no coincidence, which means that the semantic analysis and the semantic primitive extractions of the anger-type psychological adjectives in modern Chinese 
have passed verification. Conversely, if there is one or several coincidences on the semantic primitive structure attributes, which indicates that the verification is not successful, then the semantic analysis and the semantic primitive extractions need to be re-conducted and re-verified until verification is successful.

Step 5 Incorporate, optimize and build the semantic primitive set of the anger-type psychological adjectives in modern Chinese. Since the psychological adjectives in the same lexical field have both common semantic features and different semantic attributes, the semantic primitives extracted from each group must coincide with each other. Therefore, it is necessary to incorporate and optimize the semantic primitives of different groups, and then establish the semantic primitive set of the anger-type psychological adjectives in modern Chinese.

\subsection{Semantic Analysis and Semantic Primitive Extractions of the Anger-type Psychological Adjectives in Modern Chinese}

According to the semantic features of the anger-type psychological adjectives in modern Chinese and its semantic primitive structural attributes, this paper predefines several semantic primitives as the followings: Gs [object (emotion)], G[angry], Gs [polarity (negative)], Gs [degree (slight, medium, high, higher, highest)]).

The 36 anger-type psychological adjective in modern Chinese collected in this paper are put into 15 synonyms groups according to the syllable orders in Modern Chinese Dictionary ( $7^{\text {th }}$ edition). The 15 groups of the anger-type psychological adjectives in modern Chinese are also 15 minimum semantic groups. Due to limited space, this paper will choose one minimal semantic group to analyze the meanings and extract their semantic primitives.
【愤懑】<书〉气愤; 抑郁不平。

([fèn mèn] <written language> angry; depressive)

【愤慨】气愤不平。

([fèn kăi] indignant)

【赫然(2)】形容大怒。

([hè rán] furious)

Semantic analysis: The object described by the words in this group is "human", the character of this object is "emotion", the semantic core is "angry", and the polarity is negative. The style of “愤懑(fèn mèn)" is written language, beside “anger", it has the meaning of “抑郁不 平(depressive)”, since “抑郁(depressed)” is defined as “心有怨愤，不能诉说而烦闷(resentful and bored)”, “愤 懑(fèn mèn)" also has the semantic attribute of “烦闷 (boredom)”. “愤慨 (fèn kăi)” means“气愤不平 (indignant)", which exists semantic superposition, therefore its degree of "anger" is higher than that of “愤萝 (fèn mèn)". According to the statistics from CCL, both of “愤茜(fèn mèn)” and “愤慨(fèn kăi)” can be used as an adjective modifier and a predicate in sentences. “赫然(2) (hè rán)" means “大怒(furious)", so its degree of “anger” is higher, and it can only be used as an adjective modifier but not a predicate in sentences. In addition, the definition of “赫然(hè rán)” in The Chinese Dictionary 2.0 indicates that it has the meaning of “盛怒貌”(the appearance of being very angry), so it emphasizes the external manner of psychological activity, while the former two words express the internal manner. In CCL, the concordances with “愤满(fèn mèn)” , “愤慨(fèn kăi)”, and “赫然(hè rán)" are 472, 1880 and 1530 respectively, therefore their word frequency is common.

In order to clearly show the similarities and differences of the word meanings in this group, the semantic analysis table is listed below:

Table 2. Semantic analysis of the “愤满(fèn mèn)” group

\begin{tabular}{|c|c|c|c|}
\hline semanticattributes $\quad$ words & 愤港(fèn mèn) & 愤慨(fèn kăi) & 赫然(2)(hè rán) \\
\hline object & human & human & human \\
\hline character of the object & emotion & emotion & emotion \\
\hline semantic core & angry & angry & angry \\
\hline polarity & negative & negative & negative \\
\hline degree of anger & high & higher & higher \\
\hline manner & internal & internal & external \\
\hline psychological state & dynamic & static & static \\
\hline accompanying emotion & boredom & none & none \\
\hline predicate & positive & positive & negative \\
\hline attributive & positive & positive & positive \\
\hline style & written & spoken & spoken \\
\hline multi-category & negative & negative & negative \\
\hline word frequency & common & common & common \\
\hline
\end{tabular}


To sum up, the semantic primitives extracted from this group are: \{Gs[human(emotion)], G[angry], Gs[polarity(negative)], Gs [degree(high, higher)], Gs[manner(internal, external)], Gs[psychological state(dynamic, static)], G[boredom, none], Gs [pred icate(positive, negative)], Gs [attributive(positive)], Gs[style(written, spoken)], Gs[multi-category(negative)], Gs[word frequency(common)]\}

\subsection{The Semantic Primitive Set of the Anger-type Psychological Adjectives in Modern Chinese}

After analyzing word meanings of the 15 minimal semantic groups, this paper summarizes the general table of the semantic analysis and the semantic primitive extractions of the anger-type psychological adjectives in modern Chinese in order to verify them, and the detailed semantic analysis of each word is listed in the following table. (In order to save space, initials will be used. As for the semantic attributes, it has "O" for "object", "C" for "character of the object", "SC" for "semantic core", "P for "polarity", "D" for "degree of anger", "M" for "manner", "PS" for "psychological state","AE" for "accompanying emotion", " $\mathrm{P}$ " for predicate, "A" for "attributive", "S" for style, "MC" for "multi-category" and "WC" for "word frequency". As for the values, it has "H" for "human', "E" for "emotion", "A" for "anger", "IM" for internal manner, "EM" for "external manner", "DS" for "dynamic state", "SS" for "static state", "P" for "positive", "N" for "negative", "W" for "written", " $\mathrm{S}$ ", for "spoken", "C" for "common word", "UC" for "uncommon word")

Table 3. The General Semantic Analysis Table of the ATPA in Modern Chinese

\begin{tabular}{|c|c|c|c|c|c|c|c|c|c|c|c|c|c|}
\hline Word & $\mathrm{O}$ & $\mathrm{C}$ & $\mathrm{SC}$ & $\mathrm{P}^{1}$ & $\mathrm{D}$ & $\mathrm{M}$ & PS & $\mathrm{AE}$ & $\mathrm{P}^{2}$ & $\mathrm{~A}$ & $\mathrm{~S}^{1}$ & $\mathrm{MC}$ & WC \\
\hline $\begin{array}{l}\text { 愤 } \\
\end{array}$ & $\mathrm{H}$ & $\mathrm{E}$ & $\mathrm{A}$ & $\mathrm{N}$ & high & IM & DS & excitement & $\mathrm{N}$ & $\mathrm{N}$ & $\mathrm{S}^{2}$ & $\mathrm{~N}$ & $\mathrm{C}$ \\
\hline 怫 & $\mathrm{H}$ & $E$ & $\mathrm{~A}$ & $\mathrm{~N}$ & high & EM & SS & worry & $\mathrm{N}$ & $\mathrm{N}$ & $\mathrm{W}$ & $\mathrm{N}$ & UC \\
\hline 慨 (1) & $\mathrm{H}$ & $E$ & $\mathrm{~A}$ & $\mathrm{~N}$ & high & EM & DS & excitement & $\mathrm{N}$ & $\mathrm{N}$ & $\mathrm{W}$ & $\mathrm{N}$ & $\mathrm{C}$ \\
\hline 忾 & $\mathrm{H}$ & $\mathrm{E}$ & $\mathrm{A}$ & $\mathrm{N}$ & higher & IM & DS & resentment & $\mathrm{N}$ & $\mathrm{N}$ & $\mathrm{W}$ & $\mathrm{N}$ & $\mathrm{C}$ \\
\hline 茜(2) & $\mathrm{H}$ & $E$ & $\mathrm{~A}$ & $\mathrm{~N}$ & higher & IM & DS & boredom & $\mathrm{N}$ & $\mathrm{N}$ & $\mathrm{W}$ & $\mathrm{N}$ & $\mathrm{C}$ \\
\hline 恼(1) & $\mathrm{H}$ & $E$ & $\mathrm{~A}$ & $\mathrm{~N}$ & slight & IM & SS & none & $\mathrm{P}^{3}$ & $\mathrm{~N}$ & $\mathrm{~S}^{2}$ & $\mathrm{P}^{3}$ & $\mathrm{C}$ \\
\hline 怒 & $\mathrm{H}$ & $E$ & A & $\mathrm{N}$ & high & IM & SS & none & $\mathrm{P}^{3}$ & $\mathrm{~N}$ & $\mathrm{~S}^{2}$ & $\mathrm{P}^{3}$ & $\mathrm{C}$ \\
\hline 愠 & $\mathrm{H}$ & $E$ & $\mathrm{~A}$ & $\mathrm{~N}$ & medium & IM & SS & none & $\mathrm{N}$ & $\mathrm{N}$ & $\mathrm{W}$ & $\mathrm{N}$ & $\mathrm{C}$ \\
\hline 悲愤 & $\mathrm{H}$ & $\mathrm{E}$ & A & $\mathrm{N}$ & higher & IM & DS & grief & $\mathrm{P}^{3}$ & $\mathrm{P}^{3}$ & $\mathrm{~S}^{2}$ & $\mathrm{~N}$ & $\mathrm{C}$ \\
\hline $\begin{array}{l}\text { 愤愤 } \\
\end{array}$ & $\mathrm{H}$ & $E$ & A & $\mathrm{N}$ & slight & EM & SS & none & $\mathrm{N}$ & $\mathrm{P}^{3}$ & $S^{2}$ & $\mathrm{~N}$ & $\mathrm{C}$ \\
\hline 愤然 & $\mathrm{H}$ & $E$ & $\mathrm{~A}$ & $\mathrm{~N}$ & medium & EM & DS & none & $\mathrm{N}$ & $\mathrm{P}^{3}$ & $\mathrm{~S}^{2}$ & $\mathrm{~N}$ & $\mathrm{C}$ \\
\hline 愤恨 & $\mathrm{H}$ & $\mathrm{E}$ & $\mathrm{A}$ & $\mathrm{N}$ & higher & IM & DS & resentment & $\mathrm{N}$ & $\mathrm{P}^{3}$ & $\mathrm{~S}^{2}$ & $\mathrm{P}^{3}$ & $\mathrm{C}$ \\
\hline 愤激 & $\mathrm{H}$ & $\mathrm{E}$ & A & $\mathrm{N}$ & high & IM & DS & excitement & $\mathrm{P}^{3}$ & $\mathrm{P}^{3}$ & $S^{2}$ & $\mathrm{~N}$ & UC \\
\hline 激愤 & $\mathrm{H}$ & $E$ & $\mathrm{~A}$ & $\mathrm{~N}$ & high & IM & DS & excitement & $\mathrm{P}^{3}$ & $\mathrm{P}^{3}$ & $S^{2}$ & $\mathrm{~N}$ & $\mathrm{C}$ \\
\hline 愤潄 & $\mathrm{H}$ & $E$ & A & $\mathrm{N}$ & high & IM & DS & boredom & $\mathrm{P}^{3}$ & $\mathrm{P}^{3}$ & $\mathrm{~W}$ & $\mathrm{~N}$ & $\mathrm{C}$ \\
\hline 愤慨 & $\mathrm{H}$ & $E$ & $\mathrm{~A}$ & $\mathrm{~N}$ & higher & IM & SS & none & $\mathrm{P}^{3}$ & $\mathrm{P}^{3}$ & $\mathrm{~S}^{2}$ & $\mathrm{~N}$ & $\mathrm{C}$ \\
\hline $\begin{array}{l}\text { 赫然(2) } \\
\end{array}$ & $\mathrm{H}$ & $E$ & $\mathrm{~A}$ & $\mathrm{~N}$ & higher & EM & SS & none & $\mathrm{N}$ & $\mathrm{P}^{3}$ & $S^{2}$ & $\mathrm{~N}$ & $\mathrm{C}$ \\
\hline 愤怒 & $\mathrm{H}$ & $E$ & $\mathrm{~A}$ & $\mathrm{~N}$ & higher & IM & DS & excitement & $\mathrm{P}^{3}$ & $\mathrm{P}^{3}$ & $S^{2}$ & $\mathrm{~N}$ & $\mathrm{C}$ \\
\hline 狂怒 & $\mathrm{H}$ & $E$ & A & $\mathrm{N}$ & higher & IM & SS & none & $\mathrm{N}$ & $\mathrm{P}^{3}$ & $\mathrm{~S}^{2}$ & $\mathrm{~N}$ & $\mathrm{C}$ \\
\hline 怫然 & $\mathrm{H}$ & $\mathrm{E}$ & $\mathrm{A}$ & $\mathrm{N}$ & slight & EM & DS & none & $\mathrm{N}$ & $\mathrm{P}^{3}$ & $\mathrm{~W}$ & $\mathrm{~N}$ & $\mathrm{C}$ \\
\hline 怫郁 & $\mathrm{H}$ & E & A & $\mathrm{N}$ & medium & $\mathrm{IM}$ & DS & $\begin{array}{l}\text { depression } \& \\
\text { boredom }\end{array}$ & $\mathrm{N}$ & $\mathrm{N}$ & W & $\mathrm{N}$ & $\mathrm{UC}$ \\
\hline 生气(1) & $\mathrm{H}$ & $\mathrm{E}$ & $\mathrm{A}$ & $\mathrm{N}$ & slight & IM & SS & none & $\mathrm{P}^{3}$ & $\mathrm{P}^{3}$ & $\mathrm{~S}^{2}$ & $\mathrm{P}^{3}$ & $\mathrm{C}$ \\
\hline 气愤 & $\mathrm{H}$ & $E$ & A & $\mathrm{N}$ & high & IM & DS & resentment & $\mathrm{P}^{3}$ & $\mathrm{P}^{3}$ & $\mathrm{~S}^{2}$ & $\mathrm{~N}$ & $\mathrm{C}$ \\
\hline 气恼 & $\mathrm{H}$ & $\bar{E}$ & $\mathrm{~A}$ & $\mathrm{~N}$ & medium & IM & SS & none & $\mathrm{P}^{3}$ & $\mathrm{P}^{3}$ & $\mathrm{~S}^{2}$ & $\mathrm{~N}$ & $\mathrm{C}$ \\
\hline 恼火 & $\mathrm{H}$ & $\mathrm{E}$ & $\mathrm{A}$ & $\mathrm{N}$ & slight & IM & SS & none & $\mathrm{P}^{3}$ & $\mathrm{P}^{3}$ & $S^{2}$ & $\mathrm{~N}$ & $\mathrm{C}$ \\
\hline 恼怒(1) & $\mathrm{H}$ & $\mathrm{E}$ & $\mathrm{A}$ & $\mathrm{N}$ & high & IM & SS & none & $\mathrm{P}^{3}$ & $\mathrm{P}^{3}$ & $\mathrm{~S}^{2}$ & $\mathrm{P}^{3}$ & $\mathrm{C}$ \\
\hline 悻然 & $\mathrm{H}$ & $\mathrm{E}$ & $\mathrm{A}$ & $\mathrm{N}$ & higher & EM & DS & resentment & $\mathrm{N}$ & $\mathrm{N}$ & $S^{2}$ & $\mathrm{~N}$ & $\mathrm{C}$ \\
\hline 悻悻(1) & $\mathrm{H}$ & $\mathrm{E}$ & $\mathrm{A}$ & $\mathrm{N}$ & higher & EM & DS & resentment & $\mathrm{P}^{3}$ & $\mathrm{P}^{3}$ & $S^{2}$ & $\mathrm{~N}$ & $\mathrm{C}$ \\
\hline 差愤 & $\mathrm{H}$ & $\mathrm{E}$ & $\mathrm{A}$ & $\mathrm{N}$ & higher & IM & DS & shame \& guilt & $\mathrm{P}^{3}$ & $\mathrm{P}^{3}$ & $S^{2}$ & $\mathrm{~N}$ & $\mathrm{C}$ \\
\hline 忧愤 & $\mathrm{H}$ & $\mathrm{E}$ & $\mathrm{A}$ & $\mathrm{N}$ & higher & IM & DS & worry \& boredom & $\mathrm{P}^{3}$ & $\mathrm{P}^{3}$ & $\mathrm{~S}^{2}$ & $\mathrm{~N}$ & $\mathrm{C}$ \\
\hline 怨愤(1) & $\mathrm{H}$ & $\mathrm{E}$ & A & $\mathrm{N}$ & higher & IM & DS & resentment & $\mathrm{P}^{3}$ & $\mathrm{P}^{3}$ & $S^{2}$ & $\mathrm{~N}$ & $\mathrm{C}$ \\
\hline 怒冲冲 & $\mathrm{H}$ & $\mathrm{E}$ & $\mathrm{A}$ & $\mathrm{N}$ & higher & EM & DS & excitement & $\mathrm{N}$ & $\mathrm{P}^{3}$ & $\mathrm{~S}^{2}$ & $\mathrm{~N}$ & $\mathrm{C}$ \\
\hline 气冲冲 & $\mathrm{H}$ & $\mathrm{E}$ & $\mathrm{A}$ & $\mathrm{N}$ & high & EM & DS & excitement & $\mathrm{N}$ & $\mathrm{P}^{3}$ & $S^{2}$ & $\mathrm{~N}$ & $\mathrm{C}$ \\
\hline 气鼓鼓 & $\mathrm{H}$ & $\mathrm{E}$ & $\mathrm{A}$ & $\mathrm{N}$ & high & EM & SS & none & $\mathrm{N}$ & $\mathrm{P}^{3}$ & $S^{2}$ & $\mathrm{~N}$ & $\mathrm{C}$ \\
\hline 气哼哼 & $\mathrm{H}$ & $\mathrm{E}$ & $\mathrm{A}$ & $\mathrm{N}$ & higher & EM & DS & none & $\mathrm{N}$ & $\mathrm{P}^{3}$ & $S^{2}$ & $\mathrm{~N}$ & $\mathrm{C}$ \\
\hline 气呼呼 & $\mathrm{H}$ & $\mathrm{E}$ & $\mathrm{A}$ & $\mathrm{N}$ & medium & EM & SS & none & $\mathrm{N}$ & $\mathrm{P}^{3}$ & $S^{2}$ & $\mathrm{~N}$ & $\mathrm{C}$ \\
\hline
\end{tabular}


With observations and comparisons of the semantic analysis of each word in this table, this paper finds there is no coincidences between any two words, which means that the semantic analysis of these words in modern Chinese have passed the verification.

In the following steps, this paper will incorporate, optimize the semantic primitives extracted from the words in the 15 groups, and then classify them into different semantic primitive modules. Firstly, from the above table, it can be seen that words expressing accompanying emotions are not the semantic primitives but words that distinguish the meanings of the anger-type psychological adjectives in modern Chinese, therefore, they can be identified as semantic distinguishing words and marked as Gw[ ]. Secondly, as for the classification of semantic primitives, this paper takes the four modules of semantic primitives proposed by $\mathrm{Hu}$ : semantic category, semantic core, semantic attributes and pragmatic attributes. According to $\mathrm{Hu}$, semantic category refers to the semantic category to which the concept represented by a group of words belongs. Psychological adjectives are used to describe the attributes of things; therefore the semantic category of the anger-type psychological adjectives in modern Chinese is G[attribute]. Semantic core is the semantic primitives completely shared by all the words in a word set. Semantic attributes are the semantic distinguishing features of words.[4]

After incorporating all the semantic primitives and remove the duplicated ones, the original se mantic primitive set and the semantic distinguishing words of the anger-type psychological adjectives is listed below:

Table 4. The original semantic primitive set and their semantic distinguishing words of the ATPA in modern Chinese

\begin{tabular}{|l|l|}
\hline \multirow{5}{*}{ semantic category } & G[attribute] \\
\hline \multirow{5}{*}{ semantic core } & Gs[human(emotion)] \\
\cline { 2 - 2 } & G[angry] \\
\cline { 2 - 2 } & Gs[polarity(negative)] \\
\hline \multirow{5}{*}{ pragmatic attributes } & Gs[degree(slight, medium, high, higher, highest)] \\
\cline { 2 - 3 } & Gs[manner(internal, external)] \\
\cline { 2 - 3 } & Gs[psychological(static, dynamic)] \\
\hline & Gs[predicate(positive, negative)] \\
\cline { 2 - 3 } & Gs[attributive(positive, negative)] \\
\cline { 2 - 3 } & Gs[style(written,spoken)] \\
\cline { 2 - 3 } & Gs[word frequency(common, uncommon)] \\
\cline { 2 - 3 } & Gs[multi-category(negative, positive)] \\
\hline \multirow{5}{*}{ semantic distinguishing words } & $\begin{array}{l}\text { Gw[excitement], Gw[grief], Gw[worry], Gw[resentment], Gw[boredom], Gw[depression and } \\
\text { boredom], Gw[shame and guilt], Gw[worry and boredom] }\end{array}$ \\
\hline
\end{tabular}


Obviously, the semantic particle of the semantic distinguishing words such as "boredom", "depression and boredom", "shame and guilt" and "worry and boredom" in this table is too big and needs to be decomposed and optimized. It is well known that "boredom", "depression and boredom" and "worry and boredom" all belong to the same sub-category of "boredom", and the semantic core of these words can be identified as "boredom". Both "boredom" and "depression and boredom" involve one emotion of "boredom", and their differences lie in the degrees and its values. "Worry and boredom" contains "boredom" and "worry". As a result, these words should be optimized as: Gw[boredom] and Gw[worry]. "Shame and guilt" belongs to the "shame" group, and it can be optimized as $\mathrm{Gw}$ [shame].

To sum up, the semantic primitives of "boredom", "depression and boredom", "shame and guilt" and "worry and boredom" can be optimized as Gw[boredom], Gw[worry] and $\mathrm{Gw}[\mathrm{shame}]$. So far, the final semantic primitive set and the semantic distinguishing words of the anger-type psychological adjectives in modern Chinese and its semantic distinguishing words can be listed in the following table:

Table 5. The final semantic primitive set and their semantic distinguishing words of the ATPA in modern Chinese

\begin{tabular}{|c|c|}
\hline semantic category & G[attribute] \\
\hline \multirow{3}{*}{ semantic core } & Gs[human(emotion)] \\
\hline & G[angry] \\
\hline & Gs[polarity(negative)] \\
\hline \multirow{3}{*}{ semantic attributes } & Gs[degree(slight, medium, high, higher, highest)] \\
\hline & Gs $[$ manner(internal, external) $]$ \\
\hline & Gs[psychological state(static, dynamic)] \\
\hline \multirow{5}{*}{ pragmatic attributes } & Gs[predicate(positive, negative)] \\
\hline & Gs[attributive(positive, negative)] \\
\hline & Gs[style(written,spoken)] \\
\hline & Gs[word frequency (common word, uncommon word)] \\
\hline & Gs[multi-category(negative, positive)] \\
\hline semantic distinguishing words & $\mathrm{Gw}[$ excitement], Gw[grief], Gw[worry], Gw[resentment], Gw[boredom], Gw[shame] \\
\hline
\end{tabular}




\section{Conclusions}

\subsection{Summary of the Research}

Firstly, this paper takes the anger-type psychological adjectives in modern Chinese as an example, builds a word set with 36 anger-type psychological adjectives and describes their semantic features and semantic dimension attributes.

Secondly, this paper conducts the semantic analysis of the anger-type psychological adjectives and extracts its semantic primitives under the theory of semantic primitive and then establishes the semantic analysis tables for verification.

Thirdly, this paper incorporates and optimizes all the semantic primitives extracted from each minimal semantic group, divides them into four semantic primitive modules, marks the semantic distinguishing words and establishes the final semantic primitive set and its semantic distinguishing words of the anger-type psychological adjectives in modern Chinese.

\subsection{Discussion and Limitation}

Given the limitation of this research, there exist the following problems:

1. As for the entry selection criteria of the anger-type psychological adjectives in modern Chinese, this paper does not include the four-character idioms

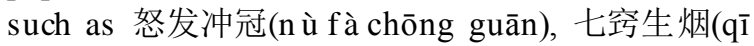
qiào shēng yān) because of the loose structures and the particularities of semantics and grammar. However, although state adjectives are formed by means of overlapping or adding suffixes on the bas is of attribute adjectives, their semantic features are different, so there must be differences in the word meanings. Therefore, it is a pity not to study the four-character idioms that describe anger in this paper.

2. The degrees of anger for the anger-type psychological adjectives in modern Chinese are valued as "slight, medium, high, higher and highest" in this paper, but whether the degrees and its value are suitable for describing the degrees of other psychological adjectives in modern Chinese remains to be discussed.

3. The polarities of the anger-type psychological adjectives in modern Chinese have both semantic polarity and pragmatic polarity. This paper only studies the semantic polarity, and the pragmatic polarity of the anger-type psychological adjectives in modern Chinese is of great research value and needs to be studied.

4. Due to limited research level, it is inevitable that the semantic particles of some semantic primitives of the anger-type psychological adjectives in modern
Chinese are too coarse, any reasonable criticisms and corrections will be warmly welcomed.

\section{Acknowledgments}

This research is supported by the National Social Science Foundation of China (Grant No. 14BYY121).

\section{REFERENCES}

[1] Goddard, Cliff and Wierzbicka, Anna. (Eds.). Meaning and Universal Grammar: Theory and Empirical Findings (2 volumes) [C]. Amsterdam/Philadelphia: John Benjamins. 2002.

[2] Cheng Zenghou. LEXICOMETRICS[M]. Jiangsu Education Press, 1987.

[3] Liu Xinglin. Brief Introduction to Lexical Semantic Knowledge Base[J]. Fu Jian Computer, 2009(9):47-49

[4] Hu Dan. Research on the Lexical Semantic Primitives of Modern Chinese for Natural Language Processing [M]. Guangdong World Publishing Co., 2014.

[5] Zhao Jiaxin. Research on the Semantic Network of Psychological Adjectives in Modern Chinese[D]. Nanjing Normal University, 2006.

[6] Li Jianming. On the Multi-category of Words[J]. Studies of the Chinese Language, 1994(1): 28-34.

[7] Zhu Dexi. A Study of Adjectives in Modern Chinese[J]. Studies in Language and Linguistics, 1956(1).

[8] Modern Chinese Dictionary (7th Edition) [M]. The Commercial Press, 2016.

[9] Tao ran, Xiao Liang, Yue Zhong, Zhang Zhidong. Dictionary of Modern Chinese Adjectives[M]. China International Broadcasting Press, 1995

[10] An Rupan, Zhao Yuling. A New Dictionary of Chinese Adjectives[M]. Economic Science Press, 2003.

[11] Zheng Dehuai, Meng Qinghai. Dictionary of Chinese Adjective Usage[M]. Hunan Publishing House, 1991.

[12] Dong Danian. Dictionary of Modern Chinese Classification [M]. Chinese Dictionary Publishing House, 1998.

[13] Chinese Dictionary 2.0 (Electronic Edition) [M]. Commercial Press (Hong Kong) Limited.

[14] Gu Yankui. Dictionary of the Origin and Development of Chinese Characters [M]. Language \& Culture Press, 2008

[15] CCL. [OL].http://ccl.pku.edu.cn

[16] [OL].http://corpus.zhonghuay uwen.org/

[17] Hao Yanping. Brief Discussion on the Methods of Seme Analy sis[J]. Journal of Heilongiiang College of Education, 2011(4).

[18] Liu Guifang. Brief Introduction to Sememe Analysis [J]. Journal of Shanxi Normal University (Social Sciences 
Edition), 1995 (2)

[19] $\mathrm{Pu}$ Dongmei. Natural Semantic Metalanguage: The Exploration of its Ideological Origin and Research on Formation Mechanism of its Theory[J]. Journal of Northwest University (Philosophy and Social Sciences Edition), 2009(3):149-151

[20] Wierzbicka, Anna. Semantics: Primes and University[M]. Oxford: Oxford University Press, 1996.

[21] Antoine Arnauld \& Pierre Nicole. Logic or the Art of Thinking[M]. Cambridge: Cambridge University Press, 1996.

[22] Zhang Jijia, Jiang Minmin. NSM Theory: Content, Development and Chanlegenes It Faces[J]. Journal of Jiaying University (Philosophy \& Social Science), 2007(3).

[23] Xing Fuyi. Modern Chinese (Revised Edition) [M]. Higher Education Press, 1993.

[24] Fu Huaiqing. Analysis and Description of Word Meanings[M], Foreign Language Teaching and Research Press, 2005.

[25] Zhang Guoxian, The Methods of quantitative measurement of Chinese Adjectives [J]. Chinese Teaching in the World, 1996(4)33-41.

[26] Shi Yuzhi, The Effect of Quantity Properties of Adjectives on Their Syntactic Behaviors $[\mathrm{J}]$. Chinese Teaching in the World, 2003(1)13-26.

[27] Baidu Encyclopedia. [OL]. https://www.baidu.com/.

[28] Wikipedia Encyclopedia. [OL].https://en.wikipedia.org/wik i/Emotion 